\section{Different Frames of Reference for Position and Motion}

\author{
E. Brenner and J. B. J. Smeets \\ Vakgroep Fysiologie, Erasmus Universiteit, 3000 DR Rotterdam, The Netherlands
}

Perception and action are believed to be based on different spatial information [1-6]; perception depending on positions relative to the surroundings and action on positions relative to the observer $[4,5]$. We reexamined this distinction by presenting subjects with a spider walking across a background. Moving the background influenced perceptual judgements of the spider's velocity, but not of the spider's position. When asked to hit the spider with a rod, motion of the background influenced the speed with which subjects moved the rod, but not the direction in which they did so. Thus, both frames of reference are used in both perception and action. We argue that the distinction is between position and motion rather than between perception and action.

A moving background that makes a target appear to move when it actually does not, or not to move when it actually does, hardly influences the accuracy with which subjects point at the target [1]. Similarly, failing to detect the displacement of a target when it occurs near the time of a saccadic eye movement does not prevent subjects from accurately pointing at or reaching for the displaced target $[2,3,7]$. These and similar findings have led to the current belief that perception and action use different spatial information [1-6]. The suggestion is that action depends on positions relative to the observer, whereas perception uses the surroundings as the frame of reference $[4,5,8]$. Indeed, although the perceived velocity of a moving object that one pursues with one's eyes is largely determined by its motion relative to the surroundings [9], subjects can hit a moving target quite accurately in the absence of such surroundings [10].

Unfortunately, in all these studies subjects reported on perceived motion or displacement, whereas the action was directed at a certain position. Thus the distinction between action and perception was confounded with one between motion and position. In the present study we examine the influences of motion of a background of randomly oriented lines on the subjects' perceptual judgements of the velocity and position of a running spider, and on the way they hit the spider with a rod.

The target was a computer simulation of a red spider running to the right across a surface of randomly oriented yellow lines. The surface appeared to coincide with a transparent screen that was about $7 \mathrm{~cm}$ in front of the computer monitor. This screen protected the monitor from being hit by the rod. To make the visible surface coincide with the protective screen we presented different images to the two eyes (at $60 \mathrm{~Hz}$ per eye) using LCD shutter spectacles. The resulting
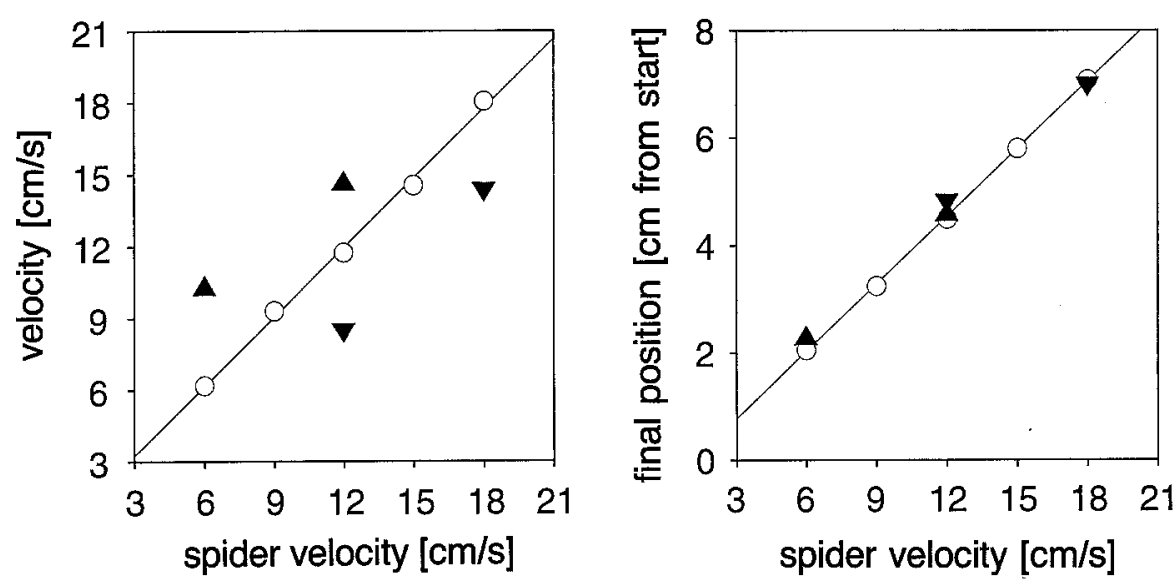

Fig. 1. Judged spider velocity and final spider position when the background was either static (O), moved at $6 \mathrm{~cm} / \mathrm{s}$ in the same direction as the spider $(\nabla)$, or moved at $6 \mathrm{~cm} / \mathrm{s}$ in the opposite direction $(\mathbf{A})$. For the velocity judgements, presentations with the red spider were alternated with ones with a green spider (on a static background). Each ran for between 250 and $500 \mathrm{~ms}$; with $500 \mathrm{~ms}$ between presentations. Subjects adjusted the velocity of the green spider to match that of the red spider. For the judgements of the spider's final position, the red spider appeared 2 to $4 \mathrm{~cm}$ to the left of the center of the screen, ran to the right for $367 \mathrm{~ms}$, and then disappeared. After another $500 \mathrm{~ms}$ the background was replaced (eliminating the external frame of reference) and the green spider appeared. Subjects moved the green spider to the position at which the red spider had disappeared. Symbols show averages of six subjects' settings (each condition presented five times, in random order). Paired $t$-tests (individual subject's mean data with and without background motion; $95 \%$ confidence limit) confirm that the moving background influences the perceived velocity in the predicted manner in all four cases. There was no significant effect of background motion on the perceived final position 
ceived motion was - at least partly - relative to the surroundings.

Despite the fact that we are very good at it, little is known about the spatial information that is used to hit a moving target [10-12]. In this study, subjects were instructed to hit spiders with a rod. They always started with the rod at a more or less fixed position, about $40 \mathrm{~cm}$ from the screen. The subjects were encouraged to

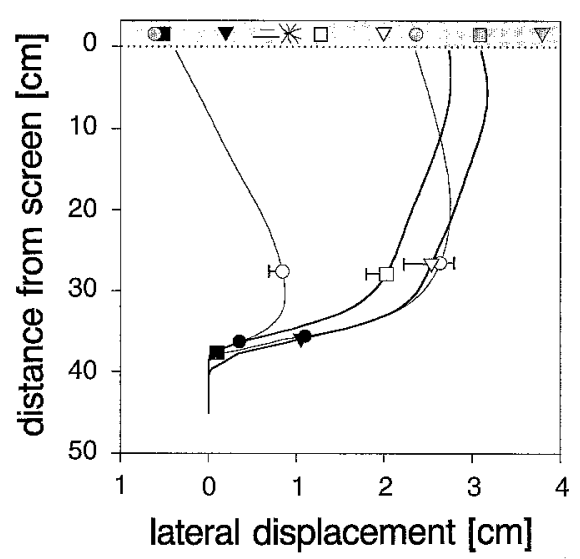

Fig. 2. Average trajectories of the tip of the rod during one subject's attempts to hit the spiders. The open and filled symbols show the average position of the rod 100 and $200 \mathrm{~ms}$ before the screen was hit (with standard errors of the lateral position at that distance from the screen). The open and filled symbols within the shaded area at the top show the corresponding lateral positions of the spider (shaded symbols show the position at the time of the hit). The thick lines show average trajectories of attempts to hit spiders running at $18 \mathrm{~cm} / \mathrm{s}$ to the right across a static background (thick line with squares) or across a background moving at $6 \mathrm{~cm} / \mathrm{s}$ in the same direction (thick line with triangles). The running spiders appeared on the screen $8 \mathrm{~cm}$ to the left (and about $40 \mathrm{~cm}$ in front) of the initial position of the rod. As the reaction time was longer (reaction times to motion onset are determined by the relative velocity [15]), and the subject hit more slowly (triangles are closer to the screen than squares) when the background moved, the spiders on the moving background had moved further to the right by the time they were hit. This difference in position is responsible for the lateral shift between the two average trajectories. Note that the trajectories themselves are very similar. The thin lines (and circles) show average trajectories of attempts to hit static spiders that were approximately at the position at which the moving spiders were either at the moment that the subject started moving the rod towards the screen (left) or at the moment that the rod actually hit the screen (right). The trajectories towards these static spiders are clearly different from those towards moving spiders hit the spider as quickly as possible by promising to give a prize to the subject who hit the spiders fastest. As a result, for most subjects, the rod accelerated until the moment of impact. Subjects knew whether they had hit the spider, because if so the spider was visibly "squashed".

We found that when the spider moved faster, subjects hit both faster and further along its path. They moved the rod less quickly towards slow spiders despite the fact that they were encouraged to hit the spider as quickly as possible. As there was no tendency to hit static spiders faster when they were further along the moving spiders' path, the different speeds with which the spiders were hit must have been due to the spiders' velocities. The tendency to hit faster spiders faster was evident from the moment the rod started moving. Thus information on the spider's motion is analyzed before starting to move the rod.

The trajectory of the rod when hitting running spiders was different from that when hitting static spiders (Fig. 2). Information on the spider's velocity is evidently not used to predict the position at which one will hit the spider in advance. Instead, the direction in which the rod is moved is influenced by the spider's constantly changing position. Thus, variations in the direction of action mainly depend on the spider's position, whereas variations in the speed of action mainly depend on the spider's velocity. This fits perfectly with the influence of the background.

The moving background did not influence the trajectory of the rod, but a background moving at $6 \mathrm{~cm} / \mathrm{s}$ in the opposite direction of the spider increased the speed of the hit to a similar extent as would an increase in spider velocity of $3 \mathrm{~cm} / \mathrm{s}$, and a background moving at $6 \mathrm{~cm} / \mathrm{s}$ in the same direction decreased the speed of the hit to a similar extent as would a decrease in spider velocity of $3 \mathrm{~cm} / \mathrm{s}$ (Fig. 3). Thus, the moving background has a similar influence on the velocity of the hit as it had on the perceived velocity; and a similar lack of influence on the direction of the hit as it had on the perceived position (compare Figs. 1 and 3).

Rather than between perception and action, the distinction appears to be between motion and position. If we want to retain a distinction between "perception" and "action" (as has been demonstrated quite convincingly in a neurological study [13]), we must accept that information is processed differently at some stage. We argue that the dissociation occurs after "properties" such as position, velocity, direction [14], size, and orientation [13] have been determined. Systematic differences in the extent to which certain percepts and actions rely on each of these "proper-
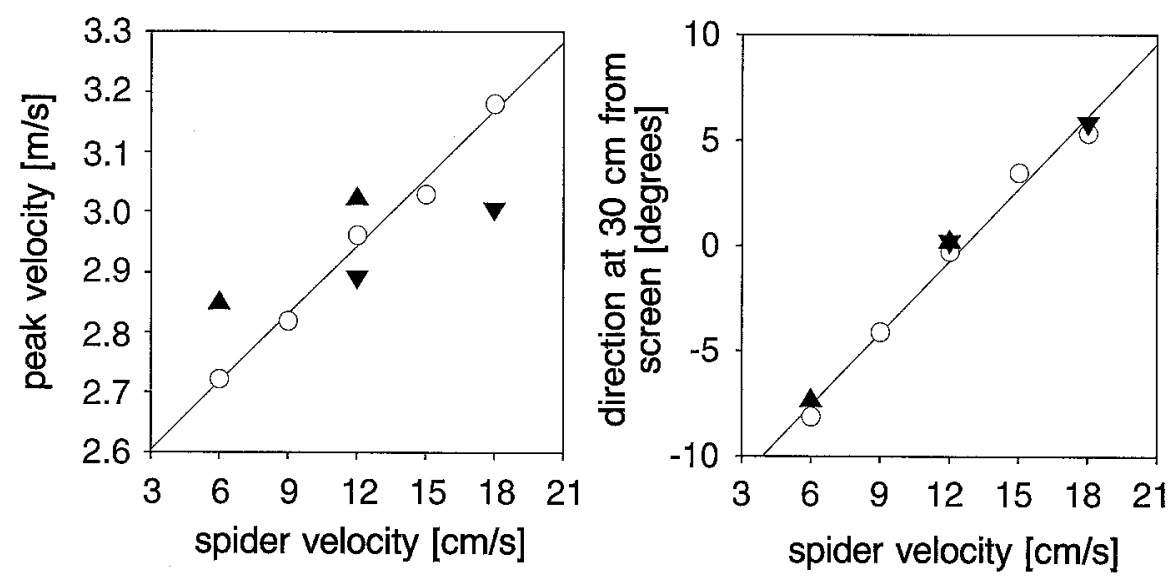

Fig. 3. Average maximal velocity with which the rod moved towards the screen and average direction of motion of the rod when $30 \mathrm{~cm}$ from the screen (relative to a line perpendicular to the screen) as a function of the velocity of the spider (12 subjects; each condition presented 18 times, in random order). The background was either static $(O)$, or moved at $6 \mathrm{~cm} / \mathrm{s}$ in the same $(\nabla)$ or the opposite (A) direction of the spider. Paired $t$-tests (individual subject's mean data with and without background motion; $95 \%$ confidence limit) confirm that the moving background influences the velocity of the hit in the predicted manner in all four cases. There was no significant effect of background motion on the direction at $30 \mathrm{~cm}$ from the screen 
ties" give the impression that perception and action use different information $[1-6,13]$.

Received April 28 and October 20, 1993

1. Bridgeman, B., Kirch, M., Sperling, A.: Percept. Psychophys. 29, 336 (1981)

2. Bridgeman, B., Lewis, S., Heit, G., Nagle, M. : J. Exp. Psychol. (Hum. Percept.) 5, 692 (1979)

3. Goodale, M. A., Pelisson, D., Prablanc, C.: Nature 320, 748 (1986)
4. Paillard, J,, in: Cognitive Processing and Spatial Orientation in Animal and Man, p. 43 (P. Ellen, C. Blanc-Thinus, eds.). 1987

5. Goodale, M. A., Milner, A. D.: Trends Neurosci. 15, 20 (1992)

6. Loomis, J. M., Da Silva, J. A., Fujita, N., Fukusima, S. S.: J. Exp. Psychol. (Hum. Percept.) 18, 906 (1992)

7. Prablanc, C., Martin, O.: J. Neurophysiol. 67, 455 (1992)

8. Howard, I. P.: Human Visual Orientation. New York: Wiley 1982

9. Brenner, E.: Vision Res. 31, 1893 (1991)
10. Hansen, R. M.: ibid. 19, 1213 (1979)

11. Bairstow, P. J.: Human Movement Sci. 6, 205 (1987)

12. Van Donkelaar, P., Lee, R. G., Gellmann, R. S.: Exp. Brain Res. 91, 151 (1992)

13. Goodale, M. A., Milner, A. D., Jakobson, L. S., Carey, D. P.: Nature 349, 154 (1991)

14. De Graaf, J. B., Sittig, A. C., Denier van der Gon, J. J.: Exp. Brain Res. 84, 434 (1991)

15. Smeets, J. B. J., Brenner, E.: Vision Res. 34, 191 (1994)

Naturwissenschaften 81, 32-34 (1994) (c) Springer-Verlag 1994

\section{Decline of Zebra Mussel Populations in the Rhine}

\section{Competition Between Two Mass Invaders (Dreissena polymorpha and Corophium curvispinum)}

G. van der Velde, B. G. P. Paffen and F. W. B. van den Brink

Laboratory of Aquatic Ecology, Catholic University Nijmegen, 6525 ED Nijmegen, The Netherlands

A. bij de Vaate

Ministry of Transport and Public Works, Institute for Inland Water Management and Waste Water Treatment, 8200 AA Lelystad, The Netherlands

H. A. Jenner

KEMA Environmental Services, 6800 ET Arnhem, The Netherlands

Originating from the basins of both the Black Sea and Caspian Sea in Europe [1], the zebra mussel (Dreissena polymorpha) invaded the Great Lakes in the USA in 1985 or 1986 [2]. A few years after its introduction in these lakes, densities of more than 700000 individuals $/ \mathrm{m}^{2}$ were recorded. Scientists in the USA are involved in a battle against what they call the Dreissena disaster, since so far no predators, parasites, or microbes seem to be able to control this mussel species [3]. In Europe, however, since 1987, zebra mussels have been on the decline in the River Rhine due to the invasion of an amphipod species originating from the same area as the zebra mussel.

The invasion of zebra mussels from the Caspian Sea basin into western Europe started two centuries ago, so that all the problems with this mussel species occurred much earlier here. It is important to note that the invasion started before the industrial revolution in the 19th century. With the construction of drinking water supply systems and the need to use surface water as process water, the engineers involved were able to adapt to unexpected problems with this fouling animal. The first problems with zebra mussels in Europe were reported by drinking water services around the end of the 19th century (Table 1). Not only was the clogging of water pipes a problem, but the taste and odor of the drinking water were also affected by the production of substances by living animals or by the decay of dead ones. Over the years, then, Europe has gained considerable experience in handling this mussel species $[4,5]$. Up to now, alleviation of fouling by the mussels in water intake pipes has been achieved by adding chlorine to the water and by heat treatment.

The sensitivity of the zebra mussel to pollution of various kinds and the fact that it accumulates various toxic substances have led to the use of these mussels as pollution biomonitors [5]. Others have proposed the use of zebra mussels as natural filters for pollutants bound to silt or phytoplankton or in lake restoration by making them filtrate algal blooms to clear highly eutrophic waters $[5,6]$.

Important factors regulating zebra mussel densities in European inland waters include the availability of solid substrates which the animals need to attach themselves, and the level of predation. In the Netherlands in particular the occurrence of solid substrates in the available waters was originally limited because the country itself was formed by the sedimentation of mud and sand supplied by the rivers Rhine and Meuse. Nowadays, however, large stony areas have been constructed for riverbank protection along the Dutch rivers. Predation on zebra mussels is mainly by water fowl, especially diving ducks (e.g., the tufted duck, Aythya fuligula), and some fish species like roach (Rutilus rutilus) and

Table 1. First records of problems with zebra mussels in Europe [11]

\begin{tabular}{cll}
\hline Year & Country & Location \\
\hline 1878 & Hungary & Budapest \\
1885 & Germany & Berlin \\
1886 & Germany & Hamburg \\
1887 & The Netherlands Rotterdam \\
1893 & France & Paris \\
\hline
\end{tabular}

